\title{
CO2 CONTENT OF ELECTRICITY LOSSES
}

\begin{abstract}
Countries are implementing policies to develop greener energy markets worldwide. In Europe, the "2030 Energy and Climate Package" asks for further reductions of green house gases, renewable sources integration, and energy efficiency targets. But the polluting intensity of electricity may be different in average than when considering market inefficiencies, in particular losses, and therefore the implemented policy must take those differences into account. Precisely, herein we study the importance in terms of $\mathrm{CO} 2$ emissions the extra amount of energy necessary to cover losses. With this purpose we use Spanish market and system data with hourly frequency from 2011 to 2013. Our results show that indeed electricity losses significantly explain $\mathrm{CO} 2$ emissions, with a higher $\mathrm{CO} 2$ emissions rate when covering losses than the average rate of the system. Additionally, we find that the market closing technologies used to cover losses have a positive and significant impact on $\mathrm{CO} 2$ emissions: when polluting technologies (coal or combined cycle) close the market, the impact of losses on $\mathrm{CO} 2$ emissions is high compared to the rest of technologies (combined heat and power, renewables or hydropower). To the light of these results we make some policy recommendations to reduce the impact of losses on $\mathrm{CO} 2$ emissions.
\end{abstract}

JEL Codes: L11; Q40; Q50; Q54

Keywords: Electricity losses; CO2 Emissions; Electricity markets

Daniel Daví-Arderius: University of Barcelona \& Chair of Energy Sustainability, IEB.

Corresponding Author (daniel davi@yahoo.es)

María-Eugenia Sanin: EPEE, Université d’Evry Val d’Essonne \& Economics Department, Ecole Polytechnique.

Elisa Trujillo-Baute: University of Barcelona, University of Warwick \& Barcelona Institute of Economics (IEB), Chair of Energy Sustainability. 


\section{INTRODUCTION}

According to IPCC estimations, the power sector has the highest contribution to green house gases (GHGs): $25 \%$ emissions were related to the electricity and the heat production in $2010^{1}$. Indeed, most regulatory efforts in terms of emission reduction around the world are mainly focused in power generation ${ }^{2}$. In Europe, 1,453 combined heat and power (CHP) generation plants have participated in the European Union Emission Trading Scheme (EU ETS), which is the regulatory instrument put in place by the European Commission (EC) in 2005 to cap CO2 emissions in line with the Kyoto Protocol targets (Berghmans and Alberola, 2013). In October 2014, the "2030 Energy and Climate Package" 3 has pushed forward the clean generation incentives by 2030 : $40 \%$ cut in GHG emissions, $27 \%$ of energy from renewable sources and $27 \%$ improvement in energy efficiency. This Package is the ambitious development of its predecessor, the "2020 Energy and Climate package" enacted in 2009 by the EC pledging for: $20 \%$ cut in GHG emissions, $20 \%$ of energy from RES-E and $20 \%$ improvement in energy efficiency. ${ }^{4}$

As stated by Guivarch and Monjon (2016), a low-carbon future world compromises energy security in Europe and is related to uncertainty regarding new technologies, fossil fuel resources, markets and economic growth. In fact, electricity systems are undergoing significant changes, mainly due to: the penetration of new renewable sources of electricity (RES-E) in the generation mix; the introduction of the information and communications technology (ICT) to monitor and grid control; the wide installation of smart meters at end-consumers, which empowers them through the implementation of demand side management (DSM) policies as well as electric vehicles (EV).

\footnotetext{
1 See IPCC 2014 report at http://mitigation2014.org/report/summary-for-policy-makers.

2 See for example the recent North American efforts: RGGI and California-Quebec CO2 market.

3 See https://ec.europa.eu/energy/en/topics/energy-strategy/2030-energy-strategy for further details.

4 The 2020 Climate and Energy Package contains Directive 2009/29/EC, Directive 2009/28/EC, Directive 2009/31/EC and Decision No. 406/2009/EC of the Parliament and the Council.
} 
The incentives implemented in most European countries to promote RES-E are helping replace the traditional most polluting technologies (coal and fuel) by non-polluting generation plants: solar, wind, geothermal, etc. This has been accompanied by the wideconnection of numerous small generation plants or distributed generation (DG). The important penetration of DG has modified the traditional top-down energy flows (Ackermann et al., 2001) ${ }^{5}$. This is the case because energy is now generated closer to consumption, which directly reduces losses. The other aforementioned changes may also affect losses: ITC technologies allow the distribution system operators (DSOs) to operate the grid more efficiently and to optimize losses; DSM policies aim to delay peak consumption to off-peak hours in order to reduce grid congestion and their correspondent losses; and EV are expected to better integrate RES and consumption, which also reduce congestion. In the end, losses represent an extra amount of energy that must be generated in the electricity systems affecting economic efficiency and, depending on how this extra energy is produced, $\mathrm{CO} 2$ emissions.

Recent literature on losses has mainly focused on the analysis of demand (DSM) and supply policies (DG/RES-E). On the one side, DSM calls on various techniques to obtain a better performance of the infrastructure, reduce the congestion problems, adapt demand to the capacity of generation at each moment in time, and reduce losses (Strbac, 2008). The slightly small potential impacts of DSM on the loss reduction are shown by Shaw et al. (2009) and Costa-Campi et. al (2016).

On the other side, the impact of DG on losses is based in their location, operation and hourly production. The decarbonisation of the electricity sector involves reconfiguring spatial patterns and potential changes in the location of the key energy system

\footnotetext{
5 It is important to note that not all RES-E plants are considered DG because some are also large plants directly connected to the transmission system operator (TSO) networks.
} 
components (Bridge et al., 2013). Indeed, an argument to justify DG is that losses related to their use are expected to be lower because the distance to consumers is also lower. However, given that losses follow a U-shape trajectory with the degree of penetration of DG (Quezada et al., 2006 and Delfanti et al., 2013), unwanted effects might counterbalance their potential benefits. This trade-off was empirically proved in the Spanish case, where solar and wind perform better in terms of losses than the rest of traditional technologies, but the opposite is true for CHP since its production profile is quite flat and not well correlated with demand (Costa-Campi et. al., 2016).

In relation to the CO2 impact of the operation of electricity power systems, numerous papers have made contributions in different directions. Ummel (2012) calculates the CO2 impact of electricity production by plant worldwide, giving birth to the CARMA database ${ }^{6}$, Marriot et al. (2010) simulate CO2 scenarios using alternative energy mixes in the U.S. and Feng et al. (2009) estimate the CO2 content of regional energy consumption in China. More recently, the attention has shifted to the air pollution avoided due to renewable installation and the evaluation of the subsidy costs with respect the decrease of social damage due to pollution reduction. Using data from the Electric Reliability Council of Texas (ERCOT) market, Novan (2015) introduces the analysis of the external benefits due to renewables, which consists on the avoided $\mathrm{CO} 2$ emissions related to each technology when the time of production and the whole generation mix are considered. He states that renewable subsidies should provide more financial support to investments that provide larger external benefits on the pollution, instead of the current homogeneous policies (see also Cullen. 2013, and Kaffine et al., 2013). Finally, the papers closest to ours are the ones that consider the $\mathrm{CO} 2$ impact of the system efficiency. This is the case of Amor et al. (2014) that documents the impact of congestion on CO2 emissions and Stoll et al. (2014) that study the impact of DSM policies by

\footnotetext{
${ }^{6}$ See http://www.carma.org.
} 
calculating an hourly $\mathrm{CO} 2$ signal applied to the hourly electricity market data in Great Britain, Ontario and Sweden. They find that load shifts from high-price to low-price hours results in carbon emission reductions, especially where price and $\mathrm{CO} 2$ intensity are positively correlated.

The previous literature review underlines the contrasted impact that electricity market design has on $\mathrm{CO} 2$ emissions. Additionally, a stylized fact in electricity markets is that, when extra generation is needed, fossil fuels are often used on account of their flexibility (in the absence of storage possibilities) increasing the $\mathrm{CO} 2$ content of the energy mix. That extra generation may also be needed due to positive shocks in demand, congestion or losses in the grids. To the best of our knowledge, the impact of electricity losses in CO2 emissions has not been studied yet, which is our objective here. The paper closest to our argument is Lindner, et al. (2013), where they compare the CO2 content of generation versus consumption among different regions in China. Hydroelectric plants are sited in the southwest, coal plants $(60 \%$ of CO2 Chinese emissions in 2010) in the north and northwest, while the growing electricity demand is in the eastern coast. They use a bottom-up model to quantify the emissions embodied in the inter-provincial flows, and find a shift of environmental pollution away from economically well-off provinces to resource-rich, and less developed provinces. Although their study highlights regional flows, they do not consider losses as a parameter in their estimations, which is also presumably significant in terms of CO2 impact. Our approach is different because we study the country as a whole to focus on the understanding of the relation between losses and the system $\mathrm{CO} 2$ emissions.

Herein we assess the CO2 impact through losses. With this purpose, we empirically estimate the $\mathrm{CO} 2$ content of power generation as a function of the transmission and distribution losses using Spanish hourly data from 2011 to 2013. In particular, we study how the extra amount of energy required to cover losses is affecting the $\mathrm{CO} 2$ emissions 
in the electric system by looking at the marginal technologies that close the market. We consider Spain because, among the five biggest economies of Europe, it had the highest share of energy generated by RES-E in 2013 (36.39\%) and its level of losses are in the average range for European countries ${ }^{7}$. From 2004 to 2013, the five biggest economies in Europe increased their RES-E share of energy production from 9.40 to $25.59 \%$ in Germany, 3.54 to $13.85 \%$ in the UK, 13.79 to $16.87 \%$ in France, 16.09 to $31.30 \%$ in Italy, and 18.98 to $36.39 \%$ in Spain. Indeed, according to our calculations, energy losses in Spain represented the $8.90 \%$ of the amount of energy injected in the grids (2012), which represented an annual cost of $1,160 \mathrm{M}^{8}$ that is borne by all consumers. According to the World Bank Database ${ }^{9}$ other European countries like Portugal and United Kingdom are in a close range with $10 \%$ and $8 \%$ losses, respectively, while the highest level of losses can be attributed to Croatia and Lithuania with $18 \%$ and $19 \%$, respectively. Our results are not only be useful for Spain, but a reference for countries that are in an earlier stage in the implementation of energy transition measures with similar levels of RES-E penetration and/or similar or higher system losses. In this sense, our paper contributes to the evaluation of the energy and climate policy imposed on the power sector through losses.

The rest of this article is organized as follows. In Section 2 we describe the data, emphasizing the relationship between system losses and $\mathrm{CO} 2$ emissions. Section 3 details our empirical strategy while section 4 includes the empirical test on the system losses contribution to the system $\mathrm{CO} 2$ emissions. Section 5 concludes and draws some policy implications.

\footnotetext{
7 Source: Eurostat Database - Short Assessment of Renewable Energy Sources (\% of electricity generation from all sources): http://ec.europa.eu/eurostat/web/energy/data/shares (last consulted on 24 September, 2015).

${ }^{8}$ Annual cost of losses by the multiplying hourly losses (MWh) by the electricity hourly Price (€/MWh). See Costa-Campi et al. (2016) for further details.

9 Source: World Bank Database - Electric power transmission and distribution losses (\% of output). http://data.worldbank.org/indicator/EG.ELC.LOSS.ZS (last consulted on 6 June, 2016).
} 


\section{DATA DESCRIPTION}

In this section we present a detailed description of the hourly data over the three-years period (2011-2013) used to perform the empirical analysis on the impact of losses on $\mathrm{CO} 2$ emissions. We start by informing on our endogenous variable: the system total $\mathrm{CO} 2$ emissions. This is followed by an apprise on the explicative variable of interest, the system losses, and on the additional control variables. Finally, we provide detailed information on the technologies operating at the margin of the market, as the key element defining the nature of the relation between the system CO2 emissions and losses.

The endogenous variable in our models is the hourly $\mathrm{CO} 2$ emissions in the electricity system $\left(\mathrm{CO} \mathrm{Tot}_{t}\right)$ considering the mix of generation in each hour, which is calculated using the hourly production by technology and their corresponding Spanish conversion factors that tell us the $\mathrm{CO} 2$ content of each technology used. Data on the generation by technology (in MWh) is obtained from the Spanish system operator (SO; see REE, 2014) and the data on conversion factors is published by the Spanish Ministry of Energy ${ }^{10}$ (in CO2 Tons per MWh with values for 2011). The conversion factors are equal to 1 for coal, 0.74 for fossil fuels, 0.41 for combined heat and power (CHP), and 0.38 for combined cycle ${ }^{11}$. Although marginal emission rates vary according to the range of production of the plants, we are considering them constant by technology, as other authors do in the literature (see Noval, 2015). On average, during the period considered, the energy mix included more than $33 \%$ from polluting technologies, and the system content reaches more than $8,220 \mathrm{CO} 2 \mathrm{Tons} / \mathrm{h}$. Considering the average load of $30,785.76 \mathrm{MWh}$, in the Spanish system around 0.27 Tons/h of $\mathrm{CO} 2$ are emitted per each MWh of energy

\footnotetext{
${ }^{10}$ More precisely, the emission factors are computed by the Institute for Energy Diversification and Saving (IDAE), ascribed to the Ministry of Industry, Energy and Tourism (information obtained from http://www.idae.es/index.php/lang.uk last consulted on 30 September, 2015).

11 The conversion factors of non-emitting technologies are cero.
} 
consumed. We will use this average when analysing the results on the system $\mathrm{CO} 2$ Tons/h per MWh for comparison purposes.

In Spain, the electricity grids with a voltage higher or equal to $220 \mathrm{kV}$ are considered transmission and are owned and operated by the Spanish TSO (Red Eléctrica de España, REE by its acronym in Spanish), while the rest are considered distribution and is owned and operated by the DSOs. Methodologically, hourly losses at each level are calculated as the difference between the sum of energy injected by all generation plants and all energy withdrawn for consumers measured at their meters. Since we consider the electricity system as a whole and we are interested in the country $\mathrm{CO} 2$ emissions, in this article we use the sum of losses in the transmission and in the distribution levels. We exclude Balearic and Canary Islands, because their specific mix of generation and operation could bias our results. They are isolated electricity grids, whose operating procedures are not the same than Spain Continental. Moreover, their generation mixes are mostly based on pollutant technologies and the sum of their demands is only about a $5 \%$ of the total demand in Spain.

Data used is published in the monthly settlement reports of the Spanish $\mathrm{SO}^{12}$, where there is hourly information from generators, TSO, DSOs and consumers, (see REE, 2014).

The resultant average hourly losses $\left(L_{t}\right)$ and total $\mathrm{CO} 2$ emissions in the system $\left(\mathrm{CO}_{2} \mathrm{Tot}_{t}\right)$ are shown in Figure 1. We observe that both variables follow a similar hourly pattern. As we will latter argue, the similarity on the series pattern may be explained by the use of the most pollutant generation as closing technologies in the peak hours. In addition, the monthly and daily averages of total CO2 emissions, presented in Tables 1

\footnotetext{
${ }^{12}$ We use the last settlement report for each month, which is the most recent data available.
} 
and 2, shows important variations within the year and the days of the week. These hourly, monthly and daily patterns call to control for load ( $\operatorname{Load}_{t}$ ) and seasonality (month $\left(M_{t}\right)$ and day of the week $\left(D O W_{t}\right)$ when we analyse the impact of losses $\left(L_{t}\right)$ on CO2 emissions in the next sections.

[FIGURE 1]

\section{[TABLE 1]}

[TABLE 2]

With the data described we perform a first test on the impact of electricity losses on the system $\mathrm{CO} 2$ emission. However, in order to obtain further insights of the nature of this relation, we study what happens at the margin when closing the electricity market.

As in most of the liberalized energy-only markets, generation plants bid their production in the wholesale market at their marginal cost in an ascending order. Each hour the more expensive technologies close the market. The integration of RES-E is causing important changes in the hourly market of electricity due to their variability and unpredictability, which requires the presence of dispatchable ${ }^{13}$ backup technologies. These factors represent a major challenge in balancing generation with consumption, whose demand profile might not match the RES production hourly. This affects the market and operation of the traditional dispatchable fossil-fired plants (coal and combined cycle) that are used to cover peak demand (Eurelectric, 2011), which in turn impacts CO2 emissions. In this context, to better understand how the extra amount of energy required to cover losses is

\footnotetext{
${ }^{13}$ Dispatchable technologies are the ones that can be regulated are flexible being able to match changes in demand and/or system requirements and which can be turned on and off based on their economic attractiveness (Eurelectric, 2011).
} 
affecting the system $\mathrm{CO} 2$ emissions, we look at the marginal technologies that close the market.

We use data on the technologies closing the market for each hour $\left(\operatorname{Tech}_{i t}\right)$ published by the Spanish market operator (OMIE), which considers a technology as closing at each hour if it is matches with and generates at least $5 \%$ of the total generation. Since the average level of losses is $7.6 \%$, this allows us to discard technologies whose hourly production is too small compared to the level of losses, being unable to cover them.

Plants are classified into: coal (CO), combined cycle (CC), hydropower (H) and special regime (SR). In Spain and according to the Electricity Sector Law 54/1997, SR includes all subsidized technologies -mostly under a feed-in-tariff scheme: RES-E (photovoltaic, solar thermal, geothermal, wind, etc.), combined heat and power (CHP) and hydropower plants with less than $50 \mathrm{MW}$ of installed capacity ${ }^{14}$. The rest of big hydropower plants (more or equal than $50 \mathrm{MW}$ ) are directly included in the $\mathrm{H}$ group. To unequivocally associate losses with specific technologies, we focus on the hours where a single technology closes alone. During the three years' period considered here, in $70 \%$ of the hours a single technology closes alone, being hydropower the most frequent with $30.3 \%$ of the hours, followed by coal with $25.5 \%$ of hours. The least frequent ones are combined cycle that closes alone only in $10.2 \%$ of hours, and special regime that close alone in $2.9 \%$ of hours. In our models, we include a dummy variable equal to one for each technology when it closes alone, and zero otherwise: $C O_{t}$ coal, $C C_{t}$ combined cycle, $S R_{t}$ special regime and $H_{t}$ hydropower. Table 3 provides full summary statistics of the variables we use to perform our empirical analysis presented in the next section.

\section{[TABLE 3]}

\footnotetext{
14 It is worth noting that the Law cited is the one that was applied during the period of study of this paper. Nowadays Special Regime covering all this technologies no longer exists.
} 


\section{EMPIRICAL APPROACH}

We have performed a stationary time series analysis to assess the proper functional form of the regression models we use. We performed two tests. First, the augmented DickeyFuller (ADF) test (Dickey and Fuller, 1979) under the null hypothesis of a unit root, and second the Kwiatkowski-Phillips-Schmidt-Shin (KPSS) tests (Kwiatkowski, et al., 1992) under the null hypothesis of stationarity. Both tests, as reported in Table 4, confirm that the series are stationary in levels, so we estimate the models using all series in levels.

\section{[TABLE 4]}

Herein we present our empirical strategy to evaluate the impact of losses on the system total $\mathrm{CO} 2$ emissions. Firstly, we analyse the system $\mathrm{CO} 2$ emissions as a function of losses to assess whether there is a significant effect, and from there we obtain an estimate of the average effect of losses on CO2 emission. Secondly, we estimate to which extent the effect of losses on the system $\mathrm{CO} 2$ emission depends on the market closing technologies as these are providing the extra generation required to cover losses.

We study whether losses are significant to explain in total $\mathrm{CO} 2$ emissions by estimating equation (1), which captures the effects of losses $\left(L_{t}\right)$ on total CO2 emissions $\left(\mathrm{CO} \mathrm{Tot}_{t}\right)$ controlling for the system load $\left(\operatorname{Load}_{t}\right)$ and seasonality patterns with the month $\left(M_{t}\right)$ and day of the week $\left(D O W_{t}\right)$. Hourly dummies would capture what happens with the inframarginal technologies in response to different system conditions during the day (including the underlying supply and demand effects). Unfortunately they cannot be included in our model due to the high correlation those dummies would have with the system load variable, provoking perfect multicollinearity that would bias our results. Combining the above consideration with the fact that system load is the best proxy to the 
system conditions at different time, we choose to include the load variable instead of the hourly dummies.

$$
\operatorname{CO} \operatorname{ToT}_{t}=\alpha_{0} L_{t}+\alpha_{1} \operatorname{Load}_{t}+\alpha_{2} M_{t}+\alpha_{3} D O W_{t}+\varepsilon_{t}
$$

After testing the effect of losses on the system $\mathrm{CO} 2$ emission, we evaluate to what extent this impact may be explained by the use of more or less pollutant generation sources as closing technologies. Hence, we assume that the closing technology in the market generates the extra amount of energy to cover losses. We are aware that this is not necessarily the case for all hours in the whole period. Nevertheless, in our data a technology is defined as "closing technology" in a certain hour if it covers at least $5 \%$ of the total generation. Given that the average level of losses is $7.6 \%$, our hypothesis remains reasonable: it is most likely that the marginal technology is used to cover -an important part of- losses in each hour. Indeed, identifying the technology or technologies that are covering the mismatch between supply and demand would require a difficult simulation exercise that is far beyond the scope of this paper. As a consequence, we consider the marginal technologies to estimate how this extra amount of energy that must be produced to cover losses affects $\mathrm{CO} 2$ emissions.

With this purpose, we modify the model to incorporate the closing technologies into the analysis (see new specification in equation 2). Accordingly, the effect that each technology has on the system $\mathrm{CO} 2$ emission $\left(C O 2 T_{0} T_{t}\right)$ is isolated through the inclusion of an interaction between the losses $\left(L_{t}\right)$ and the technology closing alone at each hour $\left(\operatorname{Tech}_{i t}\right)$.

$$
\mathrm{CO}_{\mathrm{TO} T} T_{t}=\alpha_{0} L_{t}+\alpha_{1} L_{t} \cdot \text { Tech }_{i t}+\alpha_{2} \operatorname{Load}_{t}+\alpha_{3} M_{t}+\alpha_{4} D O W_{t}+\varepsilon_{t}
$$


$T e c h_{i t}$ is a set of four dummy variables $C O_{t} ; C C_{t} ; H_{t} ; S R_{t}$, which are equal to one when the correspondent technology closes alone $\left(\mathrm{CO}_{t}\right.$ for coal, $\mathrm{CC}_{t}$ for combined cycle, $\mathrm{H}_{t}$ for hydropower, and $S R_{t}$ for special regime) and cero otherwise.

Our empirical approach relies on the assumption that in any given hour of any day between 2011 and 2013, the amount of grid losses (the difference between each hour generation injected in the grid and the amount of electricity consumed out of the grid) is exogenously given by nature: it depends on the grid structure, the location of the generation plants, the location of consumers, the generation technology and other whether and natural factors affecting the grid, both from the supply and from the demand side. Our methodological choice wishes to be simple and parsimonious. Given the assumption on the impact of the closing technology detailed above and that the variables are stationarity in levels, we use the Ordinary Least Square (OLS) method to perform the analysis.

\section{RESULTS: LOSSES CONTRIBUTION TO CO2 EMISSIONS}

Herein we present the outcomes of our empirical evaluation on the impact of losses on the system total CO2 emissions. Results from estimations of equation (1) are shown in Table 5, where each column represents a different outcome according to the variables and seasonality included. Indeed, they show that electricity losses $\left(L_{t}\right)$ explain CO2 emissions $\left(\mathrm{CO} \mathrm{Tot}_{t}\right)$ significantly, and that controlling for the system load is relevant. Considering the outcome in column (4), where both seasonality and load are included, results show that, on average, for each MWh of electricity generated to cover system losses $1.054 \mathrm{Tons} / \mathrm{h}$ of $\mathrm{CO} 2$ are emitted in the system. When comparing this result with average emission of $0.27 \mathrm{CO} 2 \mathrm{Tons} / \mathrm{h}$ per MWh of power in the system, we observe that losses not only contribute to the system emissions, but that the extra amount of energy required to cover losses is of great importance in the total system $\mathrm{CO} 2$ emissions. A 
further examination into the factors influencing the contribution of losses in $\mathrm{CO} 2$ emission might help to explore potential policy recommendation to alleviate the negatives implications of this finding.

\section{[TABLE 5]}

Results regarding the estimation of equation (2) that captures the $\mathrm{CO} 2$ emissions explained by losses when different technologies are used to close the market, are presented in Table 6.

\section{[TABLE 6]}

Since we focus on the hours when a technology closes alone, we individually estimate the effects that each technology has on the total $\mathrm{CO} 2$ emissions. From the results obtained we observe that polluting technologies -coal and combined cycle- (see columns 1 and 2) have a positive and significant effect while special regime ${ }^{15}$ and hydropower (see columns 3 and 4) have a significant and negative effect.

By looking at the sum between the estimated parameters for losses and each interaction term in Table 6, it is possible to calculate the contribution of losses to $\mathrm{CO} 2$ emissions when each technology is closing the market and most likely covering losses. In Table 7 the estimate average effects of losses in the system CO2 emissions for each closing technology. In particular, the results show that $1.29 \mathrm{Tons} / \mathrm{h}$ of $\mathrm{CO} 2$ are emitted in average for each MWh of energy generated to cover losses when coal is the marginal technology. Likewise, when combined cycle is closing alone, 1.25 Tons/h CO2 are emitted in average

15 As was explained in Section 2, SR includes: RES-E, CHP and hydropower plants of less than $50 \mathrm{MW}$. Big hydropower plants (more or equal than $50 \mathrm{MW}$ ) are directly considered in the hydropower group. 
for each MWh of energy generated to cover losses. Finally, 1.04 Tons/h CO2 and 0.96 Tons/h CO2 are emitted in average for each MWh of energy generated to cover losses when hydropower and special regime, respectively, are the marginal technologies. Note that even when the closing technology has an emission rate equal to zero (like it is the case for hydropower) the inframarginal technologies may be polluting, which makes emissions positive. The impact on our estimation due to market conditions determining the inframarginal technological mix is captured by the variable $\left(\operatorname{Load}_{t}\right)$. The estimated coefficient associated with this variable is significant across specifications, suggesting the inframarginal technologies do influence the total system emissions, but do not interact with the estimation result regarding the closing technologies. Coefficients of the closing technology variables included in each regression captures the -superior or inferior- effect of losses on $\mathrm{CO} 2$ emissions when each of the technologies matched the market.

\section{[TABLE 7]}

When comparing the results from theses technology-specific estimations with the average effect of losses obtained from the estimation of equation (1) we observe that, when coal and combined cycle are the closing technologies the contribution of losses to CO2 emission is higher than the average (1.054 Tons/h CO2), while when the closing technologies are hydropower or special regime the opposite is true. Comparing these results with the system average emissions also helps to highlight the magnitude of these effects. The case of coal is particularly concerning because when this technology is closing, in average, for each MWh of energy generated to cover losses $1.29 \mathrm{Tons} / \mathrm{h}$ of $\mathrm{CO} 2$ are emitted, while the average level of emissions in the system is $0.27 \mathrm{Tons} / \mathrm{h}$ per MWh. This means that, if coal is closing the market alone (and most probably covering losses) the polluting contribution of losses is almost 5 times more important than average. Finally, weighting one thing against another, when coal is the single technology 
closing the market, the effect from losses for each MWh of energy generated to cover losses on $\mathrm{CO} 2$ emissions is $34 \%$ higher than when the single closing technology is part of the special regime.

The coefficients of the remaining explanatory variables are very similar across the specifications. Moreover, as measures of the reliability of the statistical estimates, Tables 5 and 6 show high R-squared in all estimations. Furthermore, the models' goodness of fit are very high as shown in Figure 2 which reports the observed against the predicted values from the four models estimated using equation (2) with different technologies (numbers corresponding to numbers in Table 6 columns).

[FIGURE 2]

Our results are in line with the findings of Novan (2015) who studies the individual installation external benefits in terms of $\mathrm{CO} 2$ emissions. We find that important differences in the $\mathrm{CO} 2$ impact of losses arise when technologies that cover such losses are taken into account. Considering that the reason for those losses is in part the distant location between generation facilities and consumption, losses might represent an additional variable to include in what Novan calls the 'heterogeneous external benefits' related to each renewable technology.

\section{CONCLUDING REMARKS AND POLICY IMPLICATIONS}

Electricity systems have been transformed during the last years with the aim to improve energy security, efficiency and pollution reduction, in particular Green House Gases due to the generation mix. Up to now, electricity losses have mostly been considered a matter of efficiency indicators for TSOs, DSOs, and regulators, or as an economical cost burden 
by consumers. However, in this paper we take a step further and contribute to this debate by empirically estimating the impact that electricity losses have on $\mathrm{CO} 2$ emissions.

Our results show that losses significantly explain $\mathrm{CO} 2$ emissions. Moreover, losses' contribution to $\mathrm{CO} 2$ emissions is superior to the average emissions in the system. Finally, we find that the closing technology used to cover losses is particularly relevant to explain the previous difference in terms of emissions intensity. Indeed, when coal or combined cycle closes the market (alone), there is a significant and positive effect on $\mathrm{CO} 2$ emissions due to losses, while when special regime or hydropower are the closing technologies the impact is significant but negative, implying a lower effect from losses on the system emissions. From these results we conclude that the polluting impact of losses is important and that the closing technologies matters. These results should be taken into account in the future market design.

The policy implications derived from the previous results can be classified into two main groups: policies devoted to reduce the amount of losses and policies focused on the reduction of the $\mathrm{CO} 2$ emissions of the extra generation necessary to cover losses.

Regarding the amount of losses, the implementation of distributed generation near consumption goes in the right direction, with losses been proportional to the distance travelled by energy from generation to consumption points. Demand side management policies, which aim to reduce demand at peak periods through hourly prices of electricity, are another possibility to reduce losses by means of reducing grid congestion. Unfortunately, the impact of demand side management on losses is small (Shaw et al., 2009; Costa-Campi et al, 2016). Since losses are proportional to demand, one alternative may be to implement energy efficiency measures in both the residential and the industrial segments. 
Regarding the reduction of $\mathrm{CO} 2$ emissions in the extra generation necessary to cover losses, the penetration of RES-E is replacing the electricity generation from traditional pollutant plants. However, the wide-connection of RES-E plants is increasing the shortrun variability of the whole generation mix, which has pros and cons depending on which (complementary) solution is applied to match the random generation capacity and consumption. The use of the traditional most pollutant technologies (e.g. coal or combined cycle) as back up plants is an extended used solution up to now, but has a severe impact on $\mathrm{CO} 2$ emissions particularly relevant when covering losses, as put in evidence by our results.

In line with Novan`s (2015) results we highlight that subsidies schemes for renewables should additionally consider the individual external benefits in terms of $\mathrm{CO} 2$ emissions. Up to now, generation incentives have mostly considered the quantity of RES-E installed capacity over their locations and individual offsets in $\mathrm{CO} 2$ emissions, but no considerations on the potential emissions savings which might emerge as a result of the lower pollutant effects from zero-emission technologies acting at the margin in some hours, and hence, covering the system losses. ${ }^{16}$

In summary, electricity systems are very complex and there are several complementary policies to reduce the $\mathrm{CO} 2$ emissions effects of energy losses. The success of this path will depend on a deep understanding of its operation, features, and how to manage the equilibrium between them. Future research could extend the work on this paper in several directions to better understand the relation between losses and $\mathrm{CO} 2$ emissions, estimating the particular impact of demand-side-management policies as well as other

\footnotetext{
${ }^{16}$ But what we study in this paper is the CO2 emitted due to losses showing that the CO2 content of losses is higher than the $\mathrm{CO} 2$ content of average production.

Regulatory incentive for the future renewable capacity should take into account where the most pollutant plants and consumption are. Otherwise, new transmission grids could be necessary and the distance between new large renewable capacity and consumption could be higher, counteracting the non-pollutant effect.
} 
policies that could reduce emissions through the direct reduction of system losses. One of the closest assessments to the one presented in this paper could be the analysis of the impact of the RES-E installations location on CO2 emission through losses. Indeed, the RES-E location determines congestion as well as flows in the system. Depending on the type of RES-E this could reduce losses (like in the case of renewable distributed generation) or, on the contrary, it could increase losses (like in the case of big Hydroelectric generation). The feedback between those policies and losses as well as the consequence in terms of $\mathrm{CO} 2$ emissions should be further explored to enrich the discussion on policy' implications drown from our findings.

\section{ACKNOWLEDGEMENTS}

We are grateful for the generous support of the Chair of Energy Sustainability (Barcelona Institute of Economics, University of Barcelona), and the Generalitat de Catalunya SGR project 2015-SGR-531. Financial support from the Spanish Ministry of Economy (ECO2015-69107-R project MINECO/FEDER, UE) and FUNSEAM (Foundation for Energy and Environment Sustainability) is gratefully acknowledged. María Eugenia Sanin acknowledges support from the "Chaire Energie et Prosperité" and from the "Chaire Développement Durable EDF - X".

\section{REFERENCES:}

Ackermann, T., Andersson, G., \& Söder, L., 2001. Distributed generation: a definition. Electric power systems research, 57(3), 195-204.

Amor, M.B., Billette de Villemeur, E., Pellat, M., and Pineau, P-O. 2014. Influence of wind power on hourly electricity prices and GHG (greenhouse gas) emissions: Evidence that congestion matters from Ontario zonal data. Energy 66, 458-469.

Beaudin, M., Zareipour, H., Schellenberglabe, A., \& Rosehart, W., 2010. Energy storage for mitigating the variability of renewable electricity sources: An updated review. Energy for Sustainable Development, 14(4), 302-314. 


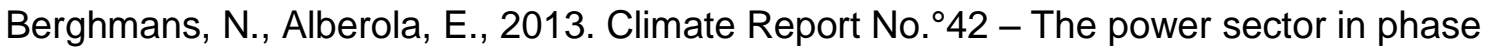
2 of the EU ETS - fewer carbon emissions, but just as much coal.

Bridge, G., Bouzarovski, S., Bradshaw, M., \& Eyre, N., 2013. Geographies of energy transition: Space, place and the low-carbon economy. Energy Policy,53, 331-340.

Costa-Campi, M.T., Daví-Arderius, D., Trujillo-Baute, E., 2016. The economic impact of electricity losses, IEB Working Paper 2016/04.

Cullen, J. A., 2013. Measuring the Environmental Benefits of Wind-Generated Electricity.American Economic Journal: Economic Policy, 5 (4): 107-33.

Delfanti, M., Falabretti, D., \& Merlo, M., 2013. Dispersed generation impact on distribution network losses. Electric Power Systems Research, 97, 10-18.

Dickey, D. A., and W.A. Fuller, 1979. Distribution of the Estimators for Autoregressive Time Series with a Unit Root, Journal of the American Statistical Association, 74 (366), 427-43.

Decision No 406/2009/EC of the European Parliament and of the Council of 23 April 2009 on the effort of Member States to reduce their greenhouse gas emissions to meet the Community's greenhouse gas emission reduction commitments up to 2020 - ELI: http://data.europa.eu/eli/dec/2009/406/oj

Directive 2009/31/EC of the European Parliament and of the Council of 23 April 2009 on the geological storage of carbon dioxide and amending Council Directive 85/337/EEC, European Parliament and Council Directives 2000/60/EC, 2001/80/EC, 2004/35/EC, 2006/12/EC, 2008/1/EC and Regulation (EC) No 1013/2006 - ELI: http://data.europa.eu/eli/dir/2009/31/oj

Directive 2009/29/EC of the European Parliament and of the Council of 23 April 2009 amending Directive 2003/87/EC so as to improve and extend the greenhouse gas emission allowance trading scheme of the Community - ELI: http://data.europa.eu/eli/dir/2009/29/oj

Directive 2009/28/EC of the European Parliament and of the Council of 23 April 2009 on the promotion of the use of energy from renewable sources and amending and subsequently repealing Directives 2001/77/EC and 2003/30/EC - ELI: http://data.europa.eu/eli/dir/2009/28/oj

Feng, K., Hubacek, K., \& Guan, D., 2009. Lifestyles, technology and CO 2 emissions in China: a regional comparative analysis. Ecological Economics, 69(1), 145-154.

Eurelectric, 2011. Flexible generation: Backing up renewables. Renewables Action Plan (RESAP), Eurelectric.

Eurelectric, 2015. Hydropower. Supporting a power system in transition. Technical report, Eurelectric.

Guivarch, C., Monjon, S, 2016. Energy security in a low-carbon world: Identifying the main uncertain drivers of energy security in Europe. Forthcoming in Energy Economics.

Kaffine, Daniel T., Brannin J. McBee, and Jozef Lieskovsky, 2013. Emissions Savings from Wind Power Generation in Texas, Energy Journal 34 (1): 155-75. 
Kwiatkowski, D., P. C. B. Phillips, P. Schmidt, and Y. Shin, 1992. Testing the Null Hypothesis of Stationarity against the Alternative of a Unit Root. Journal of Econometrics, 54, 159-178.

Lindner, S., Liu, Z., Guan, D., Geng, Y., \& Li, X., 2013. CO 2 emissions from China's power sector at the provincial level: Consumption versus production perspectives. Renewable and Sustainable Energy Reviews, 19, 164-172.

Marriott, J., Matthews, H. S., \& Hendrickson, C. T., 2010. Impact of power generation mix on life cycle assessment and carbon footprint greenhouse gas results. Journal of industrial Ecology, 14(6), 919-928.

Novan, K, 2015. Valuing the Wind: Renewable Energy Policies and Air Pollution Avoided. American Economic Journal: Economic Policy , 7(3): 291-326.

Quezada, V. H. M., J. R. Abbad, and T. G. S. Roman, 2006. Assessment of energy distribution losses for increasing penetration of distributed generation. Power Systems, IEEE Transactions on 21 (2), 533.

REE 2014. Spanish TSO website; www.esios.ree.es.

REE 2016. Red Eléctrica website; www.ree.es.

Smith, T. B. 2004. Electricity theft: a comparative analysis. Energy Policy, 32(18), 20672076.

Strbac, G. 2008. Demand side management: Benefits and challenges. Energy policy, 36(12), 4419-4426.

Stoll, P., Brandt, N., \& Nordström, L. 2014. Including dynamic CO 2 intensity with demand response. Energy Policy, 65, 490-500.

Shaw, R., Attree, M., Jackson, T., \& Kay, M. 2009. The value of reducing distribution losses by domestic load-shifting: a network perspective. Energy Policy, 37(8), 31593167.

Ummel K. 2012. CARMA Revisited: An Updated Database of Carbon Dioxide Emissions from Power Plants Worldwide, Working Paper 304 August 2012.

Wheeler, D., Ummel, K. 2008. Calculating CARMA: Global estimation of CO2 emissions from the power sector. Available at SSRN 1138690. 
Table 1. Average hourly $\mathrm{CO} 2$ emissions $\left(\mathrm{CO}^{2} \mathrm{Tot}_{t}\right)$ by day of the week.

\begin{tabular}{cccccccc}
\hline Monday & Tuesday & Wed. & Thurs. & Friday & Saturday & Sunday & Average \\
\hline 8,333 & 9,058 & 9,136 & 9,046 & 8,829 & 7,130 & 6,026 & 8,223 \\
\hline
\end{tabular}

Source: own elaboration.

Table 2. Average hourly $\mathrm{CO} 2$ emissions ( $\left.\mathrm{CO}^{2} \mathrm{Tot}_{t}\right)$ by moth.

\begin{tabular}{cccccccccccc}
\hline Jan & Feb & Mar & Apr & May & Jun & Jul & Aug & Sep & Oct & Nov & Dec \\
\hline 8,309 & 8,755 & 7,129 & 5,551 & 6,988 & 8,086 & 9,711 & 9,150 & 9,412 & 8,871 & 8,001 & 8,669 \\
\hline
\end{tabular}

Source: own elaboration.

Table 3. Summary Statistics

\begin{tabular}{lccccc}
\hline Variable & Obs. & Mean & Std. Dev. & Min & Max \\
\hline CO2Tot & 26,304 & 8220.52 & 2895.08 & 1903.46 & 16339.99 \\
$L_{t}$ & 26,304 & $2,339.97$ & 645.77 & 972.03 & $4,289.70$ \\
Load $_{t}$ & 26,304 & $30,785.76$ & $4,669.14$ & $20,319.16$ & $46,124.55$ \\
$M_{t}$ & 26,304 & 6.521 & 3.449 & 0 & 11 \\
DOW $_{t}$ & 26,304 & 2.997 & 2.001 & 0 & 6 \\
CO $_{t}$ & 26,304 & 0.255 & 0.436 & 0 & 1 \\
CC & 26,304 & 0.102 & 0.303 & 0 & 1 \\
$S R_{t}$ & 26,304 & 0.029 & 0.169 & 0 & 1 \\
$H_{t}$ & 26,304 & 0.303 & 0.459 & 0 & 1 \\
\hline
\end{tabular}

Source: own elaboration.

Table 4. ADF and KPSS tests with variables in levels

\begin{tabular}{lcc}
\hline & ADF test & KPSS test \\
\hline CO2Tot $_{t}$ & $-27.382^{\star * *}$ & 0.086 \\
$L_{t}$ & $-80.107^{\star * *}$ & 0.053 \\
Load $_{t}$ & $-64.892^{\star * *}$ & 0.075 \\
\hline
\end{tabular}

Note: Test results are statistics. The Modified Akanke Information Criterion determines lag length. The trend was not significant in any case, and hence, it was excluded. ADF null hypothesis of unit root. KPSS null hypothesis of stationarity. ${ }^{* * *}$ Significant at $1 \%$ 
Table 5. Effect of losses on total $\mathrm{CO} 2$ emissions.

\begin{tabular}{|c|c|c|c|c|}
\hline & (1) & (2) & (3) & (4) \\
\hline$L_{t}$ & $\begin{array}{l}3.420^{\star \star *} \\
(0.0067)\end{array}$ & $\begin{array}{l}0.630^{* * *} \\
(0.0439)\end{array}$ & $\begin{array}{l}2.211^{* * *} \\
(0.0163)\end{array}$ & $\begin{array}{l}1.054^{\star * *} \\
(0.0423)\end{array}$ \\
\hline Load $_{t}$ & & $\begin{array}{l}0.220^{* * *} \\
(0.0034)\end{array}$ & & $\begin{array}{l}0.128^{\star \star \star} \\
(0.0043)\end{array}$ \\
\hline Seasonality & $\mathrm{N}$ & $\mathrm{N}$ & Y & Y \\
\hline Observations & 26,304 & 26,304 & 26,304 & 26,304 \\
\hline$R$-squared & 0.907 & 0.920 & 0.938 & 0.943 \\
\hline
\end{tabular}

Table 6. Effect of losses and closing technologies on total CO2 emissions

\begin{tabular}{|c|c|c|c|c|}
\hline & (1) & (2) & (3) & (4) \\
\hline \multirow[t]{2}{*}{$L_{t}$} & $1.075^{\star * *}$ & $1.063^{\star * *}$ & $1.051^{* * *}$ & $1.040^{* * *}$ \\
\hline & $(0.0422)$ & $(0.0423)$ & $(0.0431)$ & $(0.0424)$ \\
\hline \multirow[t]{2}{*}{ Load $_{t}$} & $0.126^{\star * *}$ & $0.125^{\star * *}$ & $0.127^{\star \star \star}$ & $0.128^{\star \star *}$ \\
\hline & $(0.0043)$ & $(0.0043)$ & $(0.0043)$ & $(0.0043)$ \\
\hline \multirow[t]{2}{*}{$C O_{t} \cdot L_{t}$} & $0.207^{* * *}$ & & & \\
\hline & $(0.0131)$ & & & \\
\hline \multirow[t]{2}{*}{$C C_{t} \cdot L_{t}$} & & $0.188^{* * *}$ & & \\
\hline & & $(0.0182)$ & & \\
\hline \multirow[t]{2}{*}{$H_{t} \cdot L_{t}$} & & & $-0.011^{* \star *}$ & \\
\hline & & & $(0.0116)$ & \\
\hline \multirow[t]{2}{*}{$S R_{t} \cdot L_{t}$} & & & & $-0.074^{\star * *}$ \\
\hline & & & & $(0.0251)$ \\
\hline Seasonality & Y & Y & Y & Y \\
\hline Observations & 26,304 & 26,304 & 26,304 & 26,304 \\
\hline$R$-squared & 0.9427 & 0.9414 & 0.9453 & 0.9464 \\
\hline
\end{tabular}

Table 7. Average effects of losses on the system $\mathrm{CO} 2$ emissions for each closing technology

\begin{tabular}{lc}
\hline Closing technology & Losses effect on CO2 emissions \\
\hline Coal & 1.29 \\
Combined Cycle & 1.25 \\
Hydropower & 1.04 \\
Special Regime & 0.96 \\
\hline $\begin{array}{l}\text { Note: The contribution of losses is calculated from results in Table } 6 \\
\text { as the sum between the coefficient of losses and its interaction with } \\
\text { each technology. }\end{array}$
\end{tabular}


Figure 1. Average hourly CO2 emissions $\left(\mathrm{CO}^{2 T o t} t_{t}\right)$ and losses $\left(L_{t}\right)$.

Total CO2 emissions: hourly average

10000

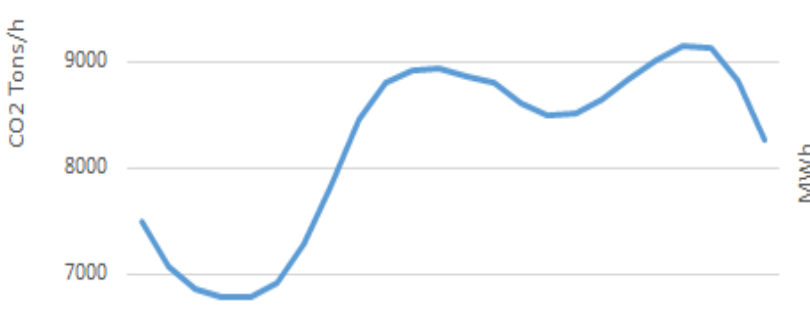

6000

1234567891011121314151617181920212223
Total Losses: hourly average

4000

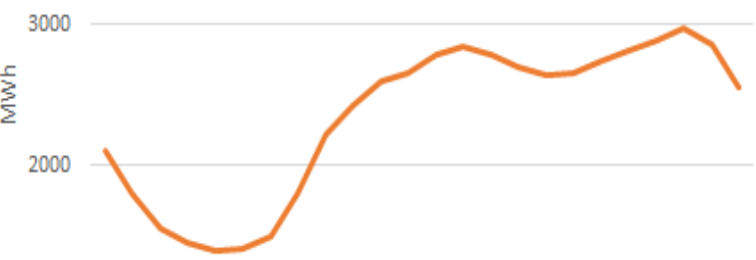

1000

1233456789101112131415161718192021222324

Source: own elaboration.

Figure 2. Goodness of fit.

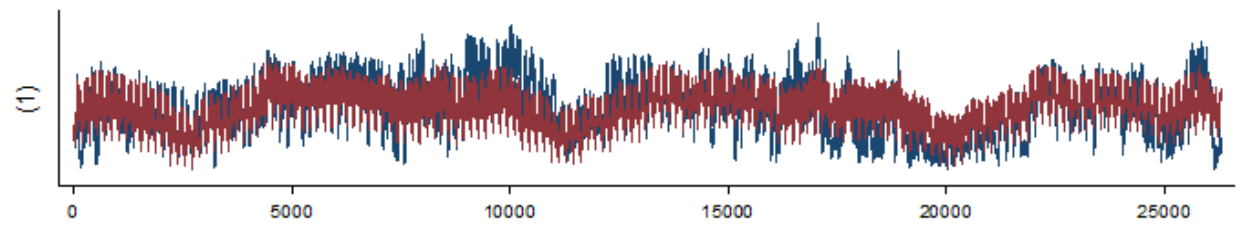

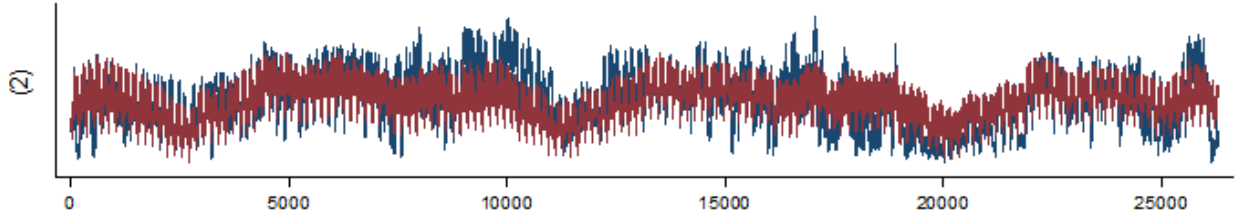
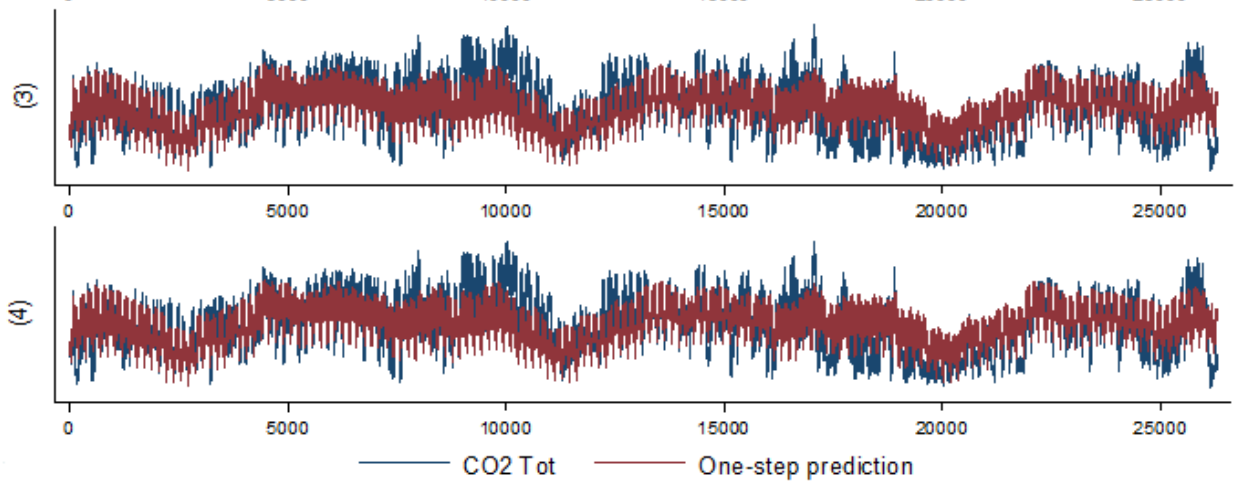

Source: own elaboration. 